\title{
JÁ NÃO TE AMO: O QUE FAZEMOS À CRIANÇA?
}

I DO NOT LOVE YOU ANYMORE: WHAT DO WE DO TO THE CHILD?

YA NO TE AMO: ¿LO QUE HACEMOS AL NIÑO?

\author{
Hugo Daniel da Cunha Lança Silva \\ https://orcid.org/0000-0003-3407-8968 / http:/ / lattes.cnpq.br/1039757637549691 / hdlanca@gmail.com \\ Instituto Politécnico de Beja, \\ Portugal.
}

\begin{abstract}
RESUMO
Cada vez mais o amor não é para o resto da vida. Porque as pessoas mudam e o amor não é eterno. Mas os filhos são e, nos despojos do casamento (ou de outra relação significativa), importa determinar o futuro das crianças. Tendo por premissa a melhor doutrina e a jurisprudência mais atual, num constante apelo à multidisciplinariedade, procuram-se diretrizes que permitam ao juiz uma decisão mais sábia, porque justa. Sem imposição de modelos, porque cada criança é um mundo.
\end{abstract}

Palavras-chave: divórcio; criança; residência.

\section{ABSTRACT}

Nowadays love is not for the rest of life. Because people change, love is not eternal. But the children are and, in the spoils of marriage (or another significant relationship), it is important to determine the future of the children. Based on the best doctrine and the most current jurisprudence, in a constant appeal for multidisciplinarity, I tried do find guidelines that will allow the judge to make a wiser decision. Without imposition of models, because every child is a world.

Keywords: divorce; child; residence.

\section{RESUMEN}

Cada vez más el amor no es para el resto de la vida. Porque la gente cambia y el amor no es eterno. Pero los hijos son $y$, en los despojos del matrimonio (o de otra relación significativa), es importante determinar el futuro de los niños. Sobre la base de la mejor doctrina y la jurisprudencia más actual, en un constante llamamiento a la multidisciplinariedad, se buscan directrices que permitan al juez una decisión más sabia, porque justa. Sin imposición de modelos, porque cada niño es un mundo.

Palabras clave: divorcio; infantil; residência.

\section{SUMÁRIO}

INTRODUÇÃO; 10 CONTEXTO DA DISSOLUÇÃO FAMILIAR; 2 AS QUESTÕES DE PARTICULAR IMPORTÂNCIA; 3 A TIPOLOGIA DA RESIDÊNCIA DA CRIANÇA; 3.1 A RESIDÊNCIA ÚNICA; 3.2 A RESIDÊNCIA PARTILHADA; 3.3 A RESIDÊNCIA ALTERNADA DOS PROGENITORES; 4 A DETERMINHAÇÃO DA RESIDÊNCIA DA CRIANÇA; 5 A ATRIBUIÇÃO DA CRIANÇA A UMA TERCEIRA PESSOA; CONCLUSÃO; REFERÊNCIAS. 


\section{INTRODUÇÃO}

É axiomático que vivemos numa época de hiper-realidade emocional, na qual as relações afetivas [jurídicas e de facto] se constroem, desconstroem e reconstroem a um ritmo frenético, em que o amor romântico é líquido e transitório e a parentalidade abandonou a estabilidade do leito conjugal, pelo que é, cada vez mais, premente refletir sobre o destino dos filhos nos escombros da relação. Sem o recurso a fórmulas matemáticas ou a modelos pré-estabelecidos, porque é preciso reconhecer a ipseidade de cada criança e as idiossincrasias de cada casal. Também por isso, neste texto, não se determinam caminhos; antes, alerta-se para as diversas soluções possíveis, sem escamotear as suas virtudes e os seus defeitos, num diálogo permanente entre a realidade jurídica e os ensinamentos recolhidos na psicologia e na sociologia, numa ótica de multidisciplinariedade, crucial no contexto do Direito das Crianças.

Para alcançar o objetivo traçado, e tendo por premissa a realidade social, analisam-se os diversos modelos existentes e as suas consequências, procurando oferecer diretrizes para o operador do Direito.

\section{O CONTEXTO DA DISSOLUÇÃO FAMILIAR}

Todos conhecemos a obra Guernica de Pablo Picasso, pintada em resposta ao bombardeamento da cidade basca que batiza a obra, uma declaração de guerra contra a guerra $e$ um manifesto contra a violência, pintada no maniqueísmo do branco e do negro. Convoco esta pintura para enfatizar que o drama e a tragédia retratadas pelo mago espanhol são os rostos que reiteradamente surgem nos processos de divórcio, interpretados [pelo menos] por um dos cônjuges desavindos como um verdadeiro atentado. Que o dilacera. Pelo que, por mais tentador que seja para a tribo dos juristas filosofar no plano do dever ser, o que tem de ser tem muita força e in casu, nos processos de divórcio encontramos pessoas feridas na sua autoestima e com a racionalidade toldada pelo desamor, por um ódio que muitas vezes ainda é amor. Porque Cazuza tem razão e por vezes te odeio por quase um segundo depois te amo mais. Pelo que, exigir-se racionalidade em plena insanidade é uma falácia.

Por outro lado, com data venia, a escolha da pintura foi feliz porque é um caminho para explicar que a hermenêutica da regulação da autoridade parental não se compatibiliza com a apreensão da temática através de um único ângulo de visão; antes, exige-se humildade para a 
analisar nas suas múltiplas perspetivas, pelo que convocar o cubismo, é uma metáfora para explicar que esta problemática exige uma interpretação na sua pluralidade.

$A b$ initio, uma desnecessidade necessária: recorro ao oxímoro para frisar que a regulação da autoridade parental é uma tríade que exige harmonizar os legítimos direitos e interesses da mãe, os legítimos interesses e direitos do pai [e outros familiares, porque o convívio com os avós, os tios e os primos é crucial para o desenvolvimento salutar da criança], sem nunca ignorar que o cerne da querela é o superior interesse daquela criança, baliza interpretativa vinculativa, omnipresente neste processo. $E$, se são três as partes envolvidas também devem ser três os advogados envolvidos [sendo que a obrigatoriedade de a criança ter um representante legal nos processos judiciais que lhe dizem respeito, é extraída do art. $4 .^{\circ}$, da Convenção Europeia sobre o Exercício dos Direitos da Criança, e deveria ser adotada como regra], de forma a que todos os interesses conflituantes sejam devidamente tutelados.

Começo, ainda, com um exórdio: nestas linhas, como em outros textos meus, cogita-se, conjugam-se dúvidas, apela-se à reflexão, porque nunca esqueço que criança se escreve no singular, que cada criança é ela própria e a sua circunstância, pelo que todas as generalizações são absurdas. Como, não ignoro, o Ideal seria a criança ser mimada por um casal que se ama (e, arrisco mesmo deixar escrito, expondo-me à tirania das críticas superficiais, por um casal heterossexual, para que a biologia se cruze com os afetos e com o mito da reunião dos papéis sociais como referência no crescimento da criança), em que os avós, maternos e paternos, continuam reciprocamente casados e têm disponibilidade emocional, física e económica, com tios e tias recetivos, com primos, preferencialmente com um tio ou tia solteiro/a e sem filhos (o que, via de regra, permite uma aproximação maior à criança). Adicionalmente, os progenitores devem ter uma confortável situação socioeconómica, predisposição para a parentalidade, ser isentos de vícios e de pecados [se não ter pecados, for uma virtude], com estabilidade emocional, e um pouco de Sorte, não fossem insondáveis os mistérios da vida. Sucede que, a realidade é quase sempre mais abjeta do que a ficção e não será coincidência que a ilha da Utopia permanece desabitada. Felizmente, quiçá, adoramos a perfeição, porque a não podemos ter; repugná-laíamos se a tivéssemos. $O$ perfeito é o desumano porque o humano é imperfeito.

\section{AS QUESTÕES DE PARTICULAR IMPORTÂNCIA}

Terminado o introito, inicio a exposição com uma questão prévia relacionada com a imperatividade de distinguir o que não pode ser miscigenado, mas que, infelizmente, tem sido 
objeto de confusão, mesmo entre os mais egrégios aplicadores e teóricos do Direito: a residência (ou guarda ${ }^{1}$, como a expressão é maioritariamente usada, embora esta aceção seja de evitar, porque credora de uma disputa por um objeto) não se confunde com o exercício da Autoridade Parental. A residência de uma criança relaciona-se com onde reside a criança, onde é o seu domicílio, enquanto que o exercício da autoridade parental relaciona-se com quem tem o poder de decidir sobre o devir da vida do menor, mormente sobre aspetos relacionados com a saúde, a educação e o seu bem estar. Se, muitas vezes, residência e autoridade parental se reúnem na(s) mesma(s) pessoa(s), nada obsta a que a criança resida exclusivamente com uma pessoa e a autoridade seja partilhada.

Mais: quando escalpelizamos a norma posta portuguesa, no que corcerne à dissolução familiar, constatamos uma nova tendência no exercício da parentalidade, que foi beber ao devir da realidade, a qual consiste no exercício em comum das responsabilidades parentais, mesmo aquando da rutura da relação entre os progenitores. Destarte, existe atualmente um regime-regra, a saber, o exercício em comum das responsabilidades parentais quanto às questões de particular importância para a vida do menor, pelo que, apenas excecionalmente é estabelecido o exercício singular das responsabilidades parentais, quando outra solução for contrária aos interesses do menor $^{2}$, exigindo-se ao tribunal a fundamentação das motivações que aconselham a que a autoridade parental seja exercida apenas por um dos progenitores.

Subscrevo a evolução legislativa porque é axiomático que este é o melhor caminho: finda a relação afetiva da qual resultou uma criança, as mais das vezes, desejada, sonhada, concebida por e com amor, devem os progenitores esquecer o que os afasta e reunirem-se em torno do que os une, colocando os interesses dos filhos acima dos seus, ab-rogando mágoas, ressentimentos, ressabiamentos, por forma a que a rutura seja o menos traumática possível para as crianças. Infelizmente, sobressai esta estranha coisa chamada realidade, e, quando o amor se transforma em ódio [ou quando o ódio ainda é amor], falta aos pais desavindos a lucidez para colocarem no epicentro das suas preocupações os interesses dos filhos que amiúde são soldados rasos numa guerra que não é sua, mártires da insensibilidade de quem tem por missão protegê-los, com prejuízo da criança que fica entre Cila e Caríbdis.

\footnotetext{
${ }^{1} 0$ legislador português parece ter querido adotar o conceito de residência em detrimento de guarda. Digo parece, porquanto, se a noção de guarda desapareceu do art. $1906 .^{\circ}$ do Código Civil Português, a mesma continua no texto do art. $1907^{\circ}$, quando se reporta à confiança da criança a terceiras pessoas; também por isso, as expressões devem ser assumidas como sinónimos, um mero eufemismo linguístico sem consequências na dogmática jurídica [salvo disposição em contrário, todas as referências legislativas referem-se ao Código Civil Português].

${ }^{2}$ Ou, por maioria de razão, em caso de impedimento ou morte do outro progenitor (art. $1903^{\circ}$ e art. $1904^{\circ}$ ).
} 
Mas, se subscrevo que o exercício conjunto das responsabilidades parentais mantém ambos os pais comprometidos com o devir do filho, e [compreendo que] está em causa um interesse público que cabe ao Estado promover ${ }^{3}$, se sustento que o exercício conjunto das autoridades parentais é um ganho civilizacional que merece ser aplaudido ${ }^{4}$, não posso ser acrítico e acreditar [Acreditar?] que esta é uma solução miraculosa, imune às maldades do mundo e dos Homens. Pelo que, a solução não pode ser automática, mas aplicada após um exame casuístico.

Regressando à norma, o legislador luso incita a que as questões de particular importância sejam decididas por ambos os pais. A rosa-dos-ventos consiste em determinar quais são essas questões $^{5}$, evitando que a indefinição legal provoque um pântano hermenêutico, que, reiteradamente é um propulsor processual das querelas pós-divórcio.

Porquanto a bonis bona disce, procurei respostas entre os mais egrégios pensadores do Direito, os quais me ensinaram que estamos perante "o conjunto de atos de fundo que constituem as traves mestras da vida da criança ou do adolescente e que compõem o núcleo essencial dos seus direitos" , ou seja, as "questões existenciais graves, que pertençam ao núcleo existencial dos direitos do filho, as questões centrais e fundamentais para o seu desenvolvimento, segurança, saúde, educação e formação, todos os actos que se relacionem com o seu futuro, a avaliar em concreto e em função das circunstâncias"”. Com data venia, neste caso, por mais eruditas que sejam as definições, estas são inaptas e oferecem mais ruído do que respostas, porquanto, é bom nunca ignorar, o Direito não é um couto de Eruditos, mas uma ordem [de valores] que visa regular as relações intersubjetivas, exigindo-se a sua compreensão quer pelo doutorado quer pelo iliterado (com data venia pelo preconceito), sendo que ao Jurista pede-se (exige-se) a capacidade de

\footnotetext{
${ }^{3}$ Cito aqui a exposição dos motivos do Projeto de Lei 509/X, que deu origem à Lei n. ${ }^{\circ} 61 / 2008$, de 31 de outubro.

${ }^{4}$ Numa posição muito crítica, Clara SOTTOMAYOR defende que "o exercício conjunto representa um retorno ao patriarcado, pois, as crianças continuam a residir com a mãe, que se sacrifica por elas no dia-a-dia, e os pais-homens têm o direito de veto sobre as decisões daquela. 0 exercício em conjunto aumenta, assim, os litígios judiciais e o risco da criança ser retirada à guarda da sua pessoa de referência, quando ela muda de cidade ou de país, provocando danos psíquicos ao desenvolvimento da criança e perturbando a estabilidade da sua relação afetiva principal com a pessoa que dela tenha cuidado" (SOTTOMAYOR, Maria Clara. Exercício conjunto das responsabilidades parentais: igualdade ou o retorno ao patriarcado. In: SOTTOMAYOR, Maria Clara e ALMEIDA, Maria Teresa. E foram felizes para sempre: uma análise crítica do novo regime jurídico do divórcio. Coimbra: Wolters Kluwer Portugal, 2010, p. 124).

${ }^{5}$ O legislador utiliza as fórmulas "questão de particular importância" e "ato de particular importância" (art. 1902. ${ }^{\circ}$ ): a melhor interpretação é que as expressões são sinónimas e a polifonia se deve a imperícia legislativa.

${ }^{6}$ MELO, Helena Gomes et. al. Poder Paternal e Responsabilidades Parentais. Lisboa, Quid Juris, 2009, p. 138.

${ }^{7}$ Fátima DUARTE, apud, RODRIGUES, Hugo Manuel Leite. Questões de Particular Importância no Exercício das Responsabilidades Parentais. Coimbra: Coimbra Editora, 2011, p. 128.
} 


\section{LDIREITO}

simplificar o complexo, tornando cognoscível o conteúdo das normas, desnudando o seu conteúdo para os brocardos que se trocam no café.

Nesse sentido, porque o legislador não nos ofereceu um elenco, nem sequer exemplificativo, justifica-se a criação de um catálogo das circunstâncias que exigem a concordância de ambos os pais, o que aqui arrisco fazer, sentado nos ombros da melhor doutrina e jurisprudência ${ }^{8}$. Assim, são questões de particular importância para a vida do filho que devem ser tomadas por ambos os pais [sempre que as mesmas não devam ser tomadas pelo filho menor, no âmbito da sua autonomia], inter alia, (i) a decisão sobre intervenção cirúrgica, (ii) a prática de atividades que envolvam risco para a saúde, integridade física e vida, incluindo as práticas desportivas, (iii) a escolha de ensino público ou particular para a escolaridade do filho e alterações escolares significativas, (iv) a mudança de residência que implique uma alteração geográfica relevante (para uma cidade distante, para as ilhas, para o estrangeiro), (v) a educação religiosa do filho, (vi) a administração ordinária dos bens, (vii) a participação em programas de televisão ou outros espetáculos, (viii) as viagens para o estrangeiro, (ix) a utilização de contracetivos e a interrupção voluntária de uma gravidez, (x) a autorização para contrair matrimónio, (xii) a perfilhação, (xiii) a propositura de ação ou apresentação de queixa-crime em representação do filho menor, e (xiv) a obtenção de carta de ciclomotores. Sublinhe-se que, a estas, podem os pais adicionar quaisquer outras que considerem pertinentes, v.g. a participação do menor nas redes sociais da internet, porquanto esta delimitação não é uma ciência exata e está dependente das dinâmicas familiares, dos costumes de cada família e das suas idiossincrasias específicas.

Por seu turno, o exercício das responsabilidades parentais relativas aos actos da vida corrente do filho cabe ao progenitor com quem ele reside habitualmente (n. ${ }^{\circ} 3$, do art. $\left.1906 .^{\circ}\right)$ e consubstancia-se nas orientações educativas não existenciais, decisões sobre questões disciplinares ligeiras, ocupação de tempos livres, horários de dormir e das refeições, tipo de alimentação e vestuário, os seus contactos sociais, decisões sobre a higiene diária, consultas médicas de rotina, utilização de dispositivos eletrónicos, e outras questões do quotidiano.

Uma nota final para enfatizar o direito a ser informado. 0 progenitor-guardião (independentemente do regime de residência) tem a obrigação de informar o outro sobre todos os factos relevantes que ocorreram na vida do menor durante o tempo em que este está à sua guarda (n. ${ }^{\circ} 6$ do. art. $1906 .^{\circ}$, por maioria de razão).

\footnotetext{
8 Porque, tal como Isaac NEWTON, entendo que, para ver mais longe, é preciso que nos coloquemos nos ombros dos gigantes.
} 


\section{LDIREITO}

\section{A TIPOLOGIA DA RESIDÊNCIA DA CRIANÇA}

Feita a destrinça entre o conceito de residência e o conceito de exercício da autoridade parental, é tempo de enfrentar o cerne da problemática e que oferece título a este texto: existindo uma dissolução da vida familiar qual deve ser o destino da criança?

Prima facie, porque a regulação do exercício da autoridade parental é uma temática fundamental da vida familiar, esta deveria ser resolvida na intimidade do casal, em decorrência do primado da autonomia da vida privada. Terminada a relação da qual existem filhos carentes de amparo e proteção, os progenitores devem ter a inteligência emocional para ab-rogar divergências e centrar as suas preocupações nos interesses dos filhos. Infelizmente, todos os dias, somos confrontados com o inverso e, pelas ruas das nossas cidades e pelos átrios dos nossos tribunais [e, tantas vezes, nas esquadras de polícia], cruzam-se casais desavindos que perderam o norte e se esqueceram que são pais.

Por outro lado, se esta é uma temática da vida privada, importa não escamotear a existência de valores de ordem pública, pelo que, o Estado, não pode plagiar Pôncio Pilates e lavar as mãos perante a infelicidade dos petizes, arrastados para uma guerra, tantas vezes, suja e porca, onde se mesuram caprichos parentais e se ignora o superior interesse dos filhos. Tenho defendido e mantenho a convicção que, dada a natureza e importância dos valores sub judice, a regulação da autoridade parental deveria passar sempre pelo crivo estatal, num processo em que, a par dos advogados dos pais, existisse um advogado da criança, com a exclusiva missão de realizar a tarefa que amiúde os pais se esquecem: defender os legítimos interesses e necessidades dos filhos do divórcio. Como, estou convicto, a regulação da autoridade parental deve sempre ser concretizada perante um tribunal, para permitir aquilatar se o acordo parental corresponde a um desejo sério e comprometido por parte dos pais e determinar se tutela efetivamente o superior interesse daquela criança em concreto.

Bem sei que, de acordo com a lei posta portuguesa, no processo de divórcio, os pais devem apresentar um acordo sobre a regulação da autoridade parental que obrigatoriamente passa pelo crivo do Ministério Público, para acautelar a sua conformidade com o superior interesse da criança9. Sucede que esta vinculação é um formalismo estéril, uma falsa sensação de proteção, porquanto

\footnotetext{
${ }^{9} \mathrm{O}$ que poderia suscitar uma questão de legitimidade do Estado para se ingerir na vida privada. Procurando resposta, encontro amparo para a minha inquietação, desde logo, no art. $8 .^{\circ}$, da Convenção dos Direitos do Homem e das Liberdades Fundamentais, do Conselho de Europa, que permite tal intervenção "quando esta
} 


\section{UDIREITO}

JÁ NÃO TE AMO: O QUE FAZEMOS À CRIANÇA?

[...] a apreciação feita pelo Ministério Público do acordo de regulação do exercício das responsabilidades parentais quando the é apresentado o processo da Conservatória reveste-se, na maioria das situações, de um caráter meramente formal. Os escassos elementos que, por regra, fluem do processo de divórcio e do próprio acordo apresentado é disso determinante, o que leva a que, na esmagadora maioria das situações, a apreciação se limite à verificação dos pressupostos legais e à confirmação se o acordo contempla as vertentes do regime que se mostra imperativo regular. ${ }^{10}$

Sublinho este ponto porque, em muitos acordos de regulação da autoridade parental, falta a vontade, requisito básico para firmar um contrato. $E$, se o pacta sunt servanda é pedra angular do edifício civilístico, importa recordar que apenas têm dignidade para ser cumpridos os acordos em que existe uma vontade livre e esclarecida; se uma vontade é coagida, não é livre; se é forjada, não é esclarecida, pelo que, não tem qualquer valor jurídico. $E$, é consabido, nos destroços do casamento há uma seara farta para ocorrerem abusos e aproveitamentos, por parte do cônjuge com posição dominante, usando a sua ascendência emocional e económica sobre o outro, para o pressionar e chantagear, o que pode determinar a aceitação, pelo cônjuge em posição mais fragilizada, de determinadas condições leoninas, apenas entendíveis à luz do desarranjo emocional coevo ao processo de divórcio.

Retomando o fio do discurso, finda a relação, existem três diferentes caminhos a trilhar, no que à residência dos filhos concerne: (i) a residência única, exclusiva ou unilateral, a (ii) residência conjunta ou partilhada e a (iii) residência alternada dos progenitores.

Com a permissão do leitor, começo pelas conclusões: nenhum dos sistemas é melhor do que o outro (ainda que, porventura, a residência alternada dos progenitores seja pior do que os demais), exigindo-se, do intérprete, uma análise casuística, de modo a determinar qual das modalidades corresponde ao superior interesse daquela criança em concreto, naquela situação espácio-temporal específica. Enfatizo este ponto, porquanto é inquietante assistir entre a doutrina de mais alto coturno e a mais egrégia jurisprudência a um lamentável fundamentalismo, quase uma futebolização do Direito, num maniqueísmo absurdo, no qual se procuram pré-determinar modelos tidos por vinculativos, no que ao destino das crianças diz respeito. Também aqui sou profundamente aristotélico e não acredito que o Direito se aplique através de fórmulas matemáticas imbuídas de pseudo-ciência, nem esqueço que aquilo que melhor serve os interesses de uma determinada criança seja trágico para outra.

ingerência estiver prevista na lei e constituir uma providência que, numa sociedade democrática, seja necessária para [...] proteção da saúde ou da moral, ou a proteção dos direitos e das liberdades de terceiros". ${ }^{10}$ LEAL, Ana Teresa. O Divórcio e as Responsabilidades Parentais. [Em Linha]. Lisboa: CEJ. [consult. 19 maio 2017]. Disponível em: www.cej.mj.pt/cej/recursos/ebooks/familia/O_divorcio.pdf., p. 172. 


\subsection{A RESIDÊNCIA ÚNICA}

Não obstante os sopros de modernidade legislativa, a tradição ainda é o que era e o modelo da residência única, com a atribuição da criança à mãe, continua a ser dominante. Dessarte, a isonomia de género contrasta com a praxis, e o cuidado com as crianças continua a ser um quase exclusivo do mundo feminino ${ }^{11}$ [em muitos casos, discute-se quem fica com a casa, o carro e as jóias, mas o destino dos filhos tende a ser um dado adquirido], pelo que, finda a relação, onerase a mãe [a troco de uma mísera pensão de alimentos que a condena à pobreza económica e ao desgaste emocional] com a obrigação de cuidar dos filhos e cumprir todas as suas múltiplas necessidades. Por seu turno, reserva-se ao pai o discreto papel de visita, tornando-se um estranho na vida dos seus filhos ou, imbuído pela "síndrome de Disneylândia", abdica da paternidade e transfigura-se num amigo, num deseducador que renuncia ao exercício da sua autoridade para sucumbir a todos os irracionais caprichos dos seus filhos. Ou, como tantas vezes acontece, reconstrói a sua vida, abdica dos seus direitos e deveres de visita e torna-se um fantasma na vida dos filhos. Que amiudadamente ficam à janela, tal como no quadro de Dalí, à espera de um pai que já não vem.

A tendência para conceder à mãe a custódia dos filhos vai beber a um tempo em que se acreditava que o melhor para a criança era, nos despojos do casamento, ficar com a mãe ${ }^{12}$, em que, por força da divisão sexual do trabalho, a mulher era formatada para se realizar enquanto esposa e mãe. Pelo que, importa sublinhar, o critério de preferência maternal não é um benefício que se atribui às mulheres (como bem sublinhou algum pensamento feminista, nos anos setenta ${ }^{13}$ ) e, latente à narrativa de que as crianças ficam melhor a mãe, está implícito o pensamento machista de que o lugar das mulheres é nas imediações do tanque e do fogão.

\footnotetext{
${ }^{11} \mathrm{O}$ que fica escrito pode ser confirmado pelos estudos de WALL, Karin. Modos de Guarda das Crianças nas Famílias Portuguesas. [Em linha]. Lisboa: "Associação Portuguesa de Sociologia”. [consult. 22 mar. 2018]. Disponível em: http://www.aps.pt/cms/docs_prv/docs/DPR462e00f42e652_1.PDF.

${ }_{12}$ Porque, hoje continua a ser verdade que "para o senso comum do cidadão em geral e, até mesmo de alguns advogados, juízes, defensores públicos e promotores de justiça, as crianças, nas hipóteses de separação, devem ficar sob os cuidados diretos da mãe. Para muitas pessoas seria um contra-senso imaginar que melhor cuidador seria o pai, pelo facto da mãe gerar a criança e mesmo não a gerando pelo enraizamento cultural existente que diz ser a mulher talhada para o cuidado das crianças, para acalentar, acalmar e melhor amparar uma criança" (VILARDO, Maria Aglaé Tedesco e FERREIRA, Nuno. A Guarda Conjunta: Notas Comparativas sobre as Soluções Legais em Vigor na União Europeia e no Brasil. Lex Familiae: Revista Portuguesa de Direito da Família, 4, n.7 (2007), p. 89).

${ }^{13}$ Conforme recorda SOTTOMAYOR, Maria Clara. Regulação do Exercício das Responsabilidades Parentais

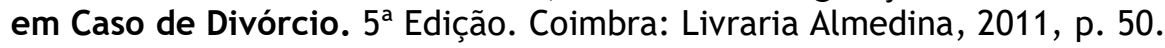




\subsection{A RESIDÊNCIA PARTILHADA}

Se é axiomático que a modernidade tarda em chegar ao lar conjugal e que a mulher continua a viver na cidade dos homens, paulatinamente perdidos entre a falocracia reinante, há homens que não se consideram seres de uma espécie superior e são suficientemente machos para mudar as fraldas dos filhos, para os levar e trazer da escola, que renunciam a tardes com os amigos para acompanharem o devir quotidiano da sua prole. Homens que, não obstante a ruína da conjugalidade, desejam manter imaculada a paternidade e têm por desejo primordial ser uma referência presente na vida dos filhos (porque se divorciaram da mulher e não das crianças), sendo tão mães como outra Mãe qualquer. Pelo que, nestes casos [e, enfatizo, nestes casos], seria um ato criminoso, aquando a rutura conjugal, negar-lhes o direito a continuar presente na vida filhos. Assertivamente, o legislador luso, em 1995, veio conceder aos pais [a estes pais!] a possibilidade de, por acordo ${ }^{14}$, optarem pelo modelo da guarda partilhada, permitindo que o divórcio não furte aos filhos a possibilidade de manterem uma relação significativa com ambos os pais.

$E$, não tenho pejo em deixar escrito neste texto, a residência partilhada é, abstratamente, o modelo que melhor se adequa à evolução da sociedade, que melhor responde aos desafios coevos da parentalidade, por ser aquele que permite às crianças e aos adolescentes conservar uma relação de proximidade e cumplicidade com ambos os pais.

Mas, o que fica escrito não significa aceitar acriticamente este regime como regra. Dessarte, não me deixo iludir por modas e lugares comuns e, se reconheço mérito à residência partilhada, não ignoro que há uma pletora de circunstâncias em que esta é proscrita. Sem preocupação de exaustividade [porque a imaginação da realidade sempre nos surpreende], este modelo é inadmissível, desde logo, quando (i) os progenitores vivem geograficamente afastados, (ii) existe um historial de violência doméstica ou conflitos graves entre os progenitores, (iii) é latente que um deles não tem estabilidade pessoal, (iv) existe um histórico de negligência ou de comportamentos que podem perigar o salutar desenvolvimento da criança, ou, (v) se estes têm modelos educativos incompatíveis (não apenas diferentes, mas incompatíveis).

\footnotetext{
${ }^{14}$ Pronunciando-se em face do regime legal anterior, mas com uma pertinência que se mantém atual, afirmase que é imprescindível a existência de acordo porque "o modelo da guarda conjunta supõe que, mesmo após o divórcio ou separação, o poder paternal seja exercido por ambos os progenitores tal como era durante a vida em comum, o que naturalmente exige acordos sucessivos e frequentes entre o pai e a mãe sobre os vários aspetos respeitantes à pessoa e bens do filho" (SIMÕES, Taborda, MARTINS, Rosa, FORMOSINHO, M. D. Regulação do Exercício do Poder Paternal: Aspectos Jurídicos e Avaliação Psicológica. In: FONSECA, António Castro et al - Psicologia forense. Coimbra. Livraria Almedina, 2006, p. 504).
} 
Efetivamente, não nos devemos ofuscar pelos méritos da residência partilhada e, ingenuamente, acreditar que este é um modelo imaculado, livre de todo e qualquer pecado. Com efeito, contrariamente a alguma opinião recentemente publicada [sobretudo nos media e redes sociais da internet], existem sólidas razões para arguir a atribuição da residência exclusiva. Desde logo, como já frisei, quando baixamos da tecnocracia utópica para sentir o latejar da realidade, as evidências obrigam a reconhecer que a democracia ainda não penetrou na intimidade do lar, incumbindo à mãe as principais responsabilidades parentais, pelo que, decorrente dessa vinculação, estabelece uma relação afetiva privilegiada com o filho, sendo o seu nome aquele que a criança grita no silêncio do sofrimento. Por outro lado, não haja ilusões nem hipocrisias: concomitantemente com os homens que lutam por este modelo porque não se imaginam a viver sem partilhar o quotidiano dos seus filhos, há aqueloutros que o requerem por mesquinhez, para melindrar a ex-companheira, para se evadirem da obrigação de prestar alimentos (sem eufemismos; a guarda partilhada é hoje utilizada como veículo de pressão e chantagem para obrigar as mulheres a aceitarem os mais tiranos acordos, pelo receio, cada vez mais fundado, de que as crianças the sejam retiradas e entregues aos progenitores), para preservar um espaço privilegiado para abusar emocional ou sexualmente dos filhos, inter alia. Pelo que, reforço o que já antes assumi, é crucial separar o trigo do joio, missão impossível de alcançar quando o Estado se limita acriticamente a homologar um acordo, sem nunca interpretar a voz dos pais, sem nunca escutar a voz das crianças.

Acresce que, se é insofismável que o modelo da residência única "acabou por revelar-se inadequado para proteger e promover o interesse da criança, designadamente o seu direito de crescer mantendo uma relação de proximidade com ambos os progenitores” ${ }^{15}$, importa enfatizar que este não é um modelo único e homogéneo, antes pode exprimir-se com diferentes cores, tons e nuances. Com efeito, não é uma inevitabilidade atribuir a criança à mãe e reservar-se para o pai o papel distante de visita, duas vezes por mês, sendo plausível [e, muitas vezes desejável] atribuir ao menor uma residência principal, na casa de um deles, mas permitindo-se ao progenitor não residente ter contactos regulares com a criança, v.g., pernoitar uma vez a meio da semana, possibilitando uma participação tão plena quanto o possível deste no devir dos seus filhos. Como a tecnologia não está destinada a afastar as pessoas, antes pode ser um meio privilegiado para construir pontes e, da mesma forma "que as cartas de amor nunca impediram os amantes de se beijar"16, as mais recentes pesquisas indicam que a internet tem permitido incrementar as

${ }^{15}$ SIMÕES, Taborda, MARTINS, Rosa, FORMOSINHO, M. D. Regulação do Exercício do Poder Paternal, cit., p. 503.

${ }^{16}$ LÉVY, Pierre. Cibercultura. Trad. Carlos Irineu da Costa. $1^{\circ}$ Ed. São Paulo: Editora 34, 1999, p. 129. 


\section{UDIREITO}

relações familiares, bem como aumentar o contato entre as pessoas que fazem parte da mesma rede pessoal de amizades ${ }^{17}$.

Uma menção final: neste texto, usei invariavelmente a expressão residência partilhada abstendo-me de escrever guarda alternada ${ }^{18}$, como amiúde surge na literatura jurídica lusitana. Fi-lo, por um lado, porque guarda me remete para coisas e não para pessoas e, por outro, o vocábulo alternada parece indiciar que compete ao progenitor que, em dado momento, reside com a criança decidir de per si sobre o quotidiano do filho. Pelo contrário, a residência partilhada exige [digo exige, porque é conditio sine qua non] que ambos os progenitores comunguem de um modelo de educação, possibilitando que a criança mantenha as mesmas rotinas e semelhantes hábitos, que the seja permitido comunicar, sem restrições, om o outro progenitor, e que as decisões relevantes sobre o seu devir sejam tomadas por acordo, da mesma forma que acontecia quando ambos os pais partilhavam a residência. Se um dos progenitores não tem maturidade emocional para compreender o salutar funcionamento da residência partilhada, então, não estão reunidos os requisitos para que esta possa ser adotada.

\subsection{A RESIDÊNCIA ALTERNADA DOS PROGENITORES}

Uma nota breve [dada a sua parca importância] para a designada residência alternada dos progenitores (bird's nest), que se caracteriza por o menor permanecer na sua residência, sendo os progenitores a alternarem de casa. Este modelo tem sido experimentado nos EUA, a título de solução provisória, e incorpora uma utopia distópica cuja benignidade é apenas aparente. Destarte, se a filosofia subjacente ao mesmo parece merecer aplauso, porquanto, de modo aparentemente altruísta, procura obstar aos inconvenientes de a criança mudar regularmente de residência, permitindo-lhe continuar a residir na sua zona de conforto, sucede que a solução congrega todos os ingredientes para fracassar e não me parece viável para além de um período curto de tempo, em que existe, por parte de um ou de ambas, expectativas de retomar a vida conjugal. Sem eufemismos: não é plausível nem saudável, que os pais abdiquem da sua identidade

17 Conforme MALAMUTH, Neil/LINZ, Daniel/YAO, Mike. The Internet and Aggression: Motivation, Disinhibitory, and Opportunity Aspects. In: AMICHAI-HAMBURGER, Yair. The Social Net. Understanding Human Behavior in Cyberspace. Oxford: Oxford University Press, 2005, p. 211.

18 Subscrevo a definição: "na guarda alternada cada progenitor decide, à sua maneira, por sua iniciativa e independentemente do outro, o que será melhor para o filho durante esse período em que possui a guarda do menor. Tudo se passa de acordo com a vontade de um só dos progenitores durante esse período de tempo em que o menor está à sua guarda. Em que um só dos progenitores concentra a autoridade parental e exerce, em pleno, o poder de decisão" (Ac. RLx 28-06-2012, disponível em www.dgsi.pt). 


\section{UDIREITO}

para viver em função das aparentes necessidades dos filhos. Mais. A estabilidade emocional dos pais é determinante para o desenvolvimento integral dos seus filhos. Por fim, se esta modalidade é exequível por semanas ou mesmo alguns, poucos, meses, bastará que o primeiro dos progenitores reconstrua o seu universo afetivo para descambar a viabilidade do modelo.

\section{A DETERMINHAÇÃO DA RESIDÊNCIA DA CRIANÇA}

Expostos os heterogéneos modelos, inexistindo acordo entre os pais [ou se o acordo não corresponder aos superiores interesses da criança], pergunta-se: como decidir sobre a residência da criança?

Começo por enfatizar que não possuo a varinha mágica de Circe que me permitiria oferecer uma fórmula matemática com a certeza magnânima de uma pseudo-objetividade científica, tantas vezes trasvestida de traje doutoral. Decidir se o superior interesse daquela criança plasma-se atribuindo a sua residência à mãe ou ao pai [ou a nenhum deles], ou determinar que se justifica uma residência partilhada, é uma decisão complexa, amiúde construída sobre as areias movediças da incerteza, que não pode erigir-se em cima da Doxa ou de preconceitos.

Dessarte, se ambos os pais concorrem no desejo sério de ter a custódia do filho, a decisão judicial deve iniciar-se "por uma selecção negativa, isto é, pela procura de aspectos a apontar fortemente contra a atribuição da guarda a um dos pais" ${ }^{19}$. Com efeito, há circunstâncias em que a residência única (e, mesmo com a proscrição ao outro do exercício da autoridade parental) é uma inevitabilidade. Assim, se não estão reunidos os requisitos que possibilitem a residência partilhada, v.g., porque os pais residem em diferentes localidades, na ausência de um acordo que respeite o superior interesse daquela criança, compete ao Tribunal decidir qual a solução mais adequada para aquela criança em concreto.

Por outro lado, quando existir

[...] uma conduta criminosa do progenitor sem a guarda (por exemplo, um crime de abuso sexual de criança ou de maus tratos, negligência nos cuidados básicos, uma conduta viciosa que ameace a estabilidade psicológica da criança (alcoolismo, toxicodependência), o facto de o progenitor sem a guarda conduzir a criança para um meio que coloca em perigo a sua segurança e formação moral (criminalidade, prostituição), a tentativa de levar a criança para o estrangeiro ou de a indispor contra o progenitor guardião, uma enfermidade física ou mental prolongada e

\footnotetext{
${ }^{19}$ SOTTOMAYOR, Maria Clara. Regulação do Exercício das Responsabilidades Parentais..., cit., p. 41.
} 
grave do progenitor sem a guarda, a oposição da criança motivada por critérios próprios, nomeadamente, por ter assistido a agressões 20 praticadas pelo pai $^{21}$,

a residência única é uma inevitabilidade. Não para punir um dos progenitores (a haver punição, deixemos aos juízos criminais o exercício da sua função), mas para proteger aquela criança.

$\mathrm{Na}$ ausência de fatores negativos a decisão tende a ser mais incerta e arbitrária, estando dependente da sensibilidade [arbitrariedade?] do julgador. Quanto muito, pode a doutrina tentar contribuir com presunções paralegais que permitam atenuar esta discricionariedade e direcionar o juiz no caminho mais correto. Assim, (i) não é discriminação apelar ao critério da preferência maternal para as crianças de tenra idade ${ }^{22}$, (ii) havendo irmãos, estes devem permanecer juntos ${ }^{23}$, (iii), deve aferir-se aquele que tem maior capacidade para comunicar e cooperar com o outro, nas matérias que afetem a criança, (iv) garantir a continuidade das relações afetivas da criança, (v) assegurar a adaptação ao ambiente extrafamiliar (a escola, os desportos que pratica, os amigos,

\footnotetext{
${ }^{20}$ No caso das agressões provocadas por um dos progenitores ao outro, parece-me, com data venia, que a mais egrégia doutrina e jurisprudência tem andado distraída: sempre que uma mulher é vítima de agressões na presença do seu filho, estamos perante dois crimes de violência doméstica: física, no caso da mulher, psicológica, no caso da criança, que assiste indefesa à agressão, pelo que, se já era moral e juridicamente censurável obrigar esta mulher a conviver com o seu agressor, in casu, o que estaríamos a fazer seria constranger a criança a relacionar-se com o seu próprio agressor, o que se traduziria numa inaceitável vitimação secundária, obviamente proscrita. Pelo exposto, aplaudo a novíssima alteração ao código civil que versa sobre a regulação das responsabilidades parentais no âmbito de crimes de violência doméstica e de outras formas de violência em contexto familiar, veio considerar que o exercício em comum das responsabilidades parentais pode ser julgado contrário aos interesses do filho se (i) for decretada medida de coação ou aplicada pena acessória de proibição de contacto entre progenitores, ou (ii) estiverem em grave risco os direitos e a segurança de vítimas de violência doméstica e de outras formas de violência em contexto familiar, como maus tratos ou abuso sexual de crianças (art. 1906. ${ }^{\circ}$-A, com a redação oferecida pela Lei.$^{\circ}$ 24/2017, de 24 de maio). A norma é prolixa, porque este raciocínio já era óbvio: no entanto, a obsessão de alguns burocratas do direito pela literalidade, aconselha estas redundâncias.

${ }^{21}$ SOTTOMAYOR, Maria Clara. Regulação do Exercício das Responsabilidades Parentais..., cit., pp. 125/126. ${ }^{22}$ Mais do que isso, estamos perante uma obrigação que resulta do disposto, no Princípio 6, da Declaração dos Direitos da Criança, proclamada pela Resolução da Assembleia das Nações Unidas, de 20 de novembro de 1959, que dispõe, salvo em circunstâncias excepcionais, a criança de tenra idade não deve ser separada da sua mãe. Sublinhe-se que, "desde a segunda metade do século XX, com as investigações de John BOWLBY e Mary AINSWORTH, que a ciência estabeleceu como aquisição inquestionável, até hoje, a importância da continuidade das vinculações afectiva precoces da criança à figura materna para o seu desenvolvimento físico, psíquico e intelectual, assim como para a sua capacidade, na idade adulta, para formar e manter relações afetivas saudáveis. Estes autores chamam a atenção para os danos causados às crianças, ao longo da sua trajetória de vida, quando são separados da figura materna ou dos seus cuidadores primários, salientando que muitas das dificuldades da infância e na idade adulta, ou psicopatologias resultam dos efeitos adversos da privação materna, a chamada disrupção da vinculação, conceito que permanece relevante nos dias de hoje" (SOTTOMAYOR, Maria Clara. Regulação do Exercício das Responsabilidades Parentais..., cit., p. 101).

${ }^{23}$ Efetivamente, "a vivência em comum, a proteção recíproca e os laços de afeto que se desenvolvem entre os irmãos é um capital de futuro do qual as crianças não devem ser privadas, a não ser em situações excecionais. A família e a sua união é um fator de estabilidade emocional que, se não podemos impor quando falamos dos pais, pelo menos tentemos preservá-lo quando se trata de irmãos" (LEAL, Ana Teresa. 0 Divórcio e as Responsabilidades Parentais, cit., p. 182).
} 
a restante família), (vi) permitir a reconstrução familiar ${ }^{24}$, (vii) aquilatar as eventuais consequências de uma mudança de residência e, mesmo, (viii) as necessidades materiais da criança [não se trata de determinar que o progenitor que recebe mais tem melhores condições para obter a custódia da criança nem de ignorar que a pensão de alimentos também existe para atenuar estas discrepâncias; tão-somente que, entre toda uma pletora de critérios, a situação económica será mais um entre muitos], bem como, (ix) qual demonstra maior apetência para priorizar as necessidades dos filhos. Como, (x) não tenho pejo em deixar escrito [ciente de que me exponho à crítica de me manter fiel a preconceitos ancestrais sobre a moral dos cônjuges], entre a miríade de critérios, também pode ser valorado qual o progenitor que mais investiu (ou qual deles desinvestiu) na manutenção da relação.

Mas, se todos estes critérios devem ser mesurados, no final do dia, "a guarda da criança deve ser confiada ao progenitor que promove o seu desenvolvimento físico, intelectual e moral, que tem mais disponibilidade para satisfazer as suas necessidades e que tem com a criança uma relação afectiva mais profunda" ${ }^{25}$, isto é, aferir qual a principal vinculação afetiva da criança, eufemismo para averiguar quem é a pessoa de referência, aquela que construiu com a criança uma relação emocional insubstituível26. Não que a atribuição da guarda à (sua) pessoa de referência seja "uma compensação pelo investimento feito no cuidado e educação da criança"27, mas porque é esta a única solução que permite a continuidade da criança no seu mundo afetivo, porquanto "a continuidade na relação psicológica principal da criança é essencial para o seu bemestar, principalmente, quando a estabilidade da família se rompe com o divórcio ou com a separação dos pais"28. Seja a mãe, o pai, a avó ou a vizinha de cima.

Pergunta-se: adotar como critério a prevalência da pessoa de referência é um eufemismo para subscrever a tese da preferência maternal? Quiçá. Mas, ainda que o seja, não é atentar contra a isonomia de género: se o critério adotado privilegia as mulheres, a culpa não é do Direito,

\footnotetext{
${ }^{24}$ Porquanto, "segundo certas análises, o bem-estar de uma criança é comparativamente mais baixo em famílias monoparentais", pelo que, se o outro progenitor vive numa família recomposta, este fator, poderá ser mesurado na decisão judicial de atribuição da criança (neste sentido, PINHEIRO, Jorge Duarte. O Direito

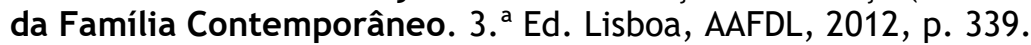

${ }^{25}$ SOTTOMAYOR, Maria Clara. Regulação do Exercício das Responsabilidades Parentais..., cit., p. 45.

${ }^{26}$ Porquanto, "a psicologia infantil demonstra que a separação da criança das suas pessoas de referência constitui um perigo emocional e mental para o seu desenvolvimento integral, provocando danos psicológicos e de saúde mental, depressões, fúrias violentas, adaptação superficial às outras pessoas, angústias, risco de instabilidade afetiva ou fuga, assim como retrocesso no desenvolvimento" (conforme Maurice BERGER, apud, SOTTOMAYOR, Maria Clara. Liberdade de Opção da Criança ou Poder do Progenitor?: Comentário ao Acórdão do Tribunal da Relação de Coimbra de 31 de Outubro de 2007. Lex Familiae. Revista Portuguesa de Direito da Família. Coimbra. a.5, n.9 (2008), p. 62).

${ }^{27}$ SOTTOMAYOR, Maria Clara. Regulação do Exercício das Responsabilidades Parentais..., cit., pp. 57/58. ${ }^{28}$ SOTTOMAYOR, Maria Clara. Regulação do Exercício das Responsabilidades Parentais..., cit., p. 58.
} 
porquanto este limita-se a traduzir o devir da realidade. Que não muda por obra e graça de um Decreto-Lei...

Por tudo, quando ambos os pais demonstram apetência para a parentalidade e a residência partilhada é inviável, porque, tal como Salomão nunca ignorou, a criança não pode dividir-se em duas partes, o cerne da problemática será determinar quem é a pessoa de referência da criança. O que nem sempre é uma missão fácil. E que não pode fazer-se de modo arbitrário ou confiando no instinto do julgador (ou no Espírito Santo). Até porque, o amadorismo tem um preço demasiado alto quando tratamos do futuro das crianças.

Dessarte, se pretendemos realizar uma análise séria sobre quem reúne as melhores condições para proteger e educar aquela criança ou adolescente, devemos enterrar o achómetro judicial e convocar peritos e especialistas de outras áreas do saber, ordenar inquéritos sociais e exames psicológicos, bem como tudo o que for necessário ou conveniente para que a decisão seja Sábia, porque Justa [e, se este processo tem custos, até os economicistas reconhecem que é bem menos dispendioso do que falhar na formação de uma criança]. Não numa lógica de interdisciplinariedade, porque o Juiz não é um especialista em todas as áreas do saber, antes, apelar à multidisciplinariedade e convocar médicos, psicólogos, assistentes sociais para, em conjunto, cada um pedalando a sua bicicleta, encontratem em conjunto as melhores soluções.

Para alcançar este desiderato, é fundamental ouvir escutar a criança, permitir-lhe o direito à palavra e à participação, como decorre dos arts. $12 .^{\circ}$ e $13 .^{\circ}$, da Convenção sobre os Direitos da Criança. 0 que, reiteradamente, é ignorado pela prática judiciária, que apenas convoca a criança quando a sua audição é imprescindível, em clara violação das normas internacionais e nacionais [suscitando, inclusive, problemas no reconhecimento das decisões junto das autoridades judiciárias estrangeiras]. Acresce que "nenhum de nós é suficientemente filósofo para saber pôrse no lugar de uma criança"29. Reitero o que já antes sublinhei: os magistrados são surdos por formação académica, pelo que escutar a criança, não é uma missão que possam realizar em exclusivo. Porque, convém ter presente, escutar a criança não é ouvir as suas palavras: escutar uma criança é interpretar os seus silêncios, os seus gestos, as suas entoações e pausas, ler o que nos dizem os seus olhos e as posições corporais, os seus desenhos, missão esta que não está sobre o manto intelectual dos juristas por mais esforçado ou bem-intencionado que seja. Até porque as crianças não se escutam de traje profissional nem em salas austeras urge carrilar a multidisciplinariedade como ferramenta para dirimir estas questões e não seja preciso a criança

${ }^{29}$ ROUSSEAU, Jean-Jacques. Emílio. Trad. Pilar Delvaulx. Mem Martins: Publicações Europa-América, 1990, p. 112. Embora, o pedagogo do iluminismo adotou Emílio, mas esqueceu-se de o ler e abandonou os seus cinco filhos. 
chorar, para que os magistrados acreditem que foi vítima de abuso sexual ${ }^{30}$. Pelo que, enfatizo, é preciso munir os tribunais de família de equipas multidisciplinares que reúnam assistentes sociais, psicólogos, médicos para que, em paridade com os juízes, no âmbito das suas distintas competências, seja possível derrubar as barreiras de iniquidade que amiúde lavram nestes processos.

\section{A ATRIBUIÇÃO DA CRIANÇA A UMA TERCEIRA PESSOA}

Se a atribuição da autoridade parental de uma criança aos seus pais parece corresponder à natureza das coisas, uma vez que a criança não é uma ilha, antes nasce no seio de uma família estabelecendo com esta uma convivência profunda da qual resulta a criação de sólidos e, tantas vezes, inquebráveis vínculos de afetividade; se, via de regra, são os pais aqueles que melhor a conhecem, e, em teoria, aqueles que estão mais habilitados para desempenhar a missão parental, atenta a "vocação natural dos seus progenitores" 31 , é ilidível que nem sempre assim acontece. Dessarte,

[...]há vários tipos de mitos ${ }^{32}$ - os que são fábulas meramente legitimadoras, e os que são, pelo contrário, fundamentos simbólicos do que mais caro e sagrado há entre os Homens. Os primeiros impedem o acesso à verdade das coisas (ou à nossa verdade possível sobre elas); os segundos são, por vezes, o único caminho possível para o conhecimento de realidades demasiado complexas, meandrosas, ou obscuras $^{33}$.

A crença de que a convivência com a família biológica é o que melhor acautela os superiores interesses de uma criança é, simultaneamente, um fundamento simbólico que impede o acesso à verdade das coisas e o único caminho possível para o conhecimento da realidade complexa do

\footnotetext{
${ }^{30}$ Refiro-me a: Abusos sexuais: há juízes que só acreditam se a "criança chorar. [Em linha]. Público. Lisboa. [consult. 22 de jun. 2017] Disponível em: https://www.publico.pt/2017/01/23/sociedade/noticia/hamagistrados-que-dizem-tenho-de-ver-a-crianca-chorar-a-minha-frente-1758965.

${ }^{31}$ MARTINS, Rosa. Responsabilidades Parentais no Século XXI: a Tensão entre o Direito de Participação da Criança e a Função Educativa dos Pais. Lex familiae: Revista Portuguesa de Direito da Familia. Coimbra. a.5, n.10 (2008), p. 37.

32 "As palavras mãe, pai e filho designam realidades que são especificamente humanas, fundadoras da nossa cultura. Não são apenas a resultante de comportamentos instintivos. Sustentam imagens interiores estruturantes do psiquismo e condicionantes da saúde mental do indivíduo. Estão, ainda, ligadas a idealizações e construções culturais de enorme peso [...] Formam um mundo em si, onde começam todos os mundos e que explica todos os mundos" (DINIZ, João Seabra. Família Lugar dos Afetos. In: LEANDRO, Armando, LÚCIO, Álvaro Laborinho. Estudos em Homenagem a Rui Epifânio. Coimbra: Livraria Almedina, 2010, p. 148).

${ }^{33}$ CUNHA, Paulo Ferreira da. Geografia Constitucional: Sistemas Juspolíticos e Globalização. Lisboa: Quid Juris, 2009, pp. 11/12.
} 
amor filial. Dessarte, é uma verdadeira crença, que tem tanto de empírico como de irracional, que o melhor para a criança é a sua entrega à família biológica. Infelizmente, este mito parece ter guarida constitucional, através do primado da inseparabilidade dos pais dos filhos, e proteção pelo direito internacional, cuja melhor interpretação parece exigir que, mesmo quando os progenitores exuberantemente comprovem inaptidão para desempenhar as suas responsabilidades parentais, se deve esperar, ridiculamente, por uma reabilitação iluminada que transforme os progenitores em pais $^{34}$.

Dito isto, se subscrevo a premissa de que as crianças têm o direito de ser educadas pelos seus pais [e não confundo este direito com o direito dos pais educarem os seus filhos], importa consagrar a destrinça entre o conceito de pais e o conceito de progenitores. Progenitor é aquele do qual alguém descende, aquele que gera, que dá origem e está umbilicalmente arreigado ao (pre)conceito biológico da filiação, incompatível com as novas conceções sociológicas e jusbiológicas da parentalidade, com a dimensão afetiva, cultural e jurídica que hoje se lhe reconhece; assim, a expressão "pais" surge como metáfora para pessoa de referência, ou seja, o adulto que tem "desempenhado as tarefas relacionadas com o cuidado e a responsabilização diária pela criança, traduzindo-se nos seguintes factos: a satisfação das necessidades básicas da criança com a alimentação e cuidados de saúde; o planeamento das refeições; o acto de acordar e de deitar a criança; a assistência na doença; o ensino das regras de etiqueta e de higiene; tarefas ligadas à interacção social e actividades lúdicas; participação em desportos e visitas a amigos; supervisão das ocupações diárias e da educação da criança, incluindo a educação, religiosa, moral, cultural e social; a assistência nos trabalhos de casa à criança em idade escolar; conselho e apoio ao processo de desenvolvimento e bem-estar emocional da criança; organização de interacção com outros membros da família, incluindo avós, primos e tios”35. Porque, "acontece que, ser pai, não corresponde unicamente a laços de sangue. Ser pai implica carinho, proteção, atenção, segurança, capacidade para formar, tratar, cuidar. Um pai é alguém que vela o sono das crianças, que brinca com elas, que as lava, veste e ajuda a comer e a vestir-se, que as ensina a andar e a

\footnotetext{
${ }^{34}$ Escreve-se: "a jurisprudência da "biologia" consiste numa violência psicológica para os sentimentos da criança e num obstáculo ao seu livre desenvolvimento, e significa a persistência, no sistema judicial, de uma mentalidade, que encara a criança como um objeto, que necessita apenas de uma casa e de alimentação, e que desconhece a importância do afecto e da relação emocional para o seu crescimento e felicidade" (SOTTOMAYOR, Maria Clara. Qual é o Interesse da Criança? Identidade Biológica Versus Relação Afectiva. In: CORREIA, Paulo [et al.] Volume Comemorativo dos 10 Anos do Curso de Pós-Graduação "Proteção de Menores - Prof. Doutor F. M. Pereira Coelho. Coimbra: Faculdade de Direito da Universidade de Coimbra, Centro de Direito da Família, 2008, p. 52).

${ }^{35}$ SOTTOMAYOR, Maria Clara. Liberdade de Opção da Criança ou Poder do Progenitor?, cit., pp. 56/57.
} 
falar, que lhes permite crescerem em paz, com a única preocupação de serem verdadeiramente crianças"36.

A suscetibilidade de a criança ser entregue a terceiros, independentemente das ações ou omissões dos pais que coloquem os filhos numa situação de risco para a sua saúde física, psicológica ou emocional, é um avanço civilizacional na defesa dos legítimos direitos das crianças, sobretudo numa "cultura judiciária que coloca os direitos dos pais biológicos no centro das decisões judiciais e que tem a fantasia ou a esperança de recuperação da imagem parental, é muito raro que seja decretada uma inibição do poder paternal ${ }^{37}$, mesmo em casos de violência, maus tratos e abuso sexual da criança pelo pai biológico" ${ }^{38}$. Em outra perspetiva, constata-se o reconhecimento de um truísmo reiteradamente ignorado: o superior interesse da criança não significa que esta seja necessariamente educada pelos seus progenitores.

Assim, subjacente à atribuição do cuidado com a criança à pessoa de referência, ao in loco parentis, porque seu verdadeiro cuidador, ainda que destituído de laços biológicos ou do vínculo jurídico da adoção, existe um princípio que importa enfatizar: o princípio da substância da parentalidade. Trata-se do reconhecimento jurídico do brocardo popular pais são aqueles que criam e aceitar que o amor pode gerar uma relação mais importante de que os vínculos biológicos ${ }^{39}$, reconhecer que a parentalidade não se afere pela procriação, mas é um processo contínuo, ininterrupto, uma sequência de pequenos atos, construindo paulatinamente com o desenvolvimento da criança uma "parentalidade de facto", que não pode ser abruptamente interrompida pelos singelos caprichos dos progenitores ou pela insensibilidade do julgador.

\footnotetext{
${ }^{36}$ AMORIM, Rui Jorge Guedes Faria. O Interesse do Menor: um Conceito Transversal à Jurisdição de Família e Crianças. Revista do CEJ. Lisboa. n.12 (2.sem.2009), p. 93.

37 A atribuição do menor a terceira pessoa não implica, necessariamente, que se retire aos pais as responsabilidades parentais, conforme se infere do texto do artigo $1907 .^{\circ}$ (quando o filho seja confiado a terceira pessoa, cabem a esta os poderes e deveres dos pais que forem exigidos pelo adequado desempenho das suas funções), aquilo que, nas palavras de Pires de LIMA e Antunes VARELA, a lei permite "que se deixem nas mãos de ambos os progenitores ou de um deles alguns farrapos do tecido do poder paternal, dificilmente determináveis, e se confie, ao mesmo tempo, a terceiro, a parte mais nobre dessa peça" (LIMA, Pires de e VARELA, Antunes. Código Civil Anotado. v. V. Reimpressão. Coimbra: Coimbra Editora, 2011, p. 405). 38 SOTTOMAYOR, Maria Clara. Qual é o Interesse da Criança?, cit., p. 46.

39 Uma proposta ousada, como todo o seu pensamento, é abraçada por John HOLT que defende a possibilidade de os pais trocarem de filhos, temporária ou definitivamente; o A. alude ao facto de que amar os filhos não é uma inevitabilidade, pelo que, é possível que alguns pais desempenhassem melhor as suas responsabilidades com filhos de terceiros, do que com os seus próprios filhos (HOLT, John. Escape for Childhood: the Needs and Rights of Children. Medford: HoltGWS, 2013, pp. 135 e ss.).
} 


\section{LDIREITO}

Escrevo ciente que as minhas palavras contrastam com anos e anos de essencialismo biológico, de sacralização dos genes, o que torna complexa a construção de um noção social de paternidade baseada em afetos e gestos objetivos de amor, carinho e interesse ${ }^{40}$.

Por tudo, e não obstante a conceção biológica da parentalidade, começamos a encontrar uma abertura crescente a soluções diferentes que consistem em fazer prevalecer os vínculos afetivos sobre a questão sanguínea, fazendo recair a escolha do cuidador da criança em alguém que não sejam os pais das crianças, mesmo que inexistam razões de censurabilidade para que estes, ou um destes, exerçam as responsabilidades parentais; um caminho no qual o afetivo vence o biológico, triunfando sobre o mito (ou uma convicção profunda sustentada em séculos de história), que os pais são os melhores cuidadores possíveis para os seus filhos.

\section{CONCLUSÃO}

Neste texto, cogitaram-se dúvidas, porque Descartes tem razão. E, num primeiro momento, procurou sensibilizar-se o leitor para as ambiguidades inerentes à atribuição da custódia dos filhos no rescaldo da ligação afetiva dos seus pais.

Posteriormente, apresentaram-se as diversas soluções possíveis, enfatizando-se em cada parágrafo, que a decisão final é sempre casuística, dissecadas as idiossincrasias de cada criança e de cada família. Num constante apelo à multidisciplinariedade; é preciso que o jurista cultive a humildade de reconhecer de que não é dono do saber universal, pelo que precisa de se reunir de especialistas de outras ciências, para o coadjuvarem numa missão que é inapto para desempenhar na solidão do seu gabinete. Especialmente em temáticas tão complexas e sensíveis como o devir de uma criança.

Porque se grande é a poesia, a bondade e as danças, mas o melhor do mundo são as crianças, dos adultos em geral e dos juristas em particular estas têm o direito de exigir o melhor de nós. $\mathrm{E}$, no que a estes temas dizem respeito, o melhor de nós ainda está para chegar.

\footnotetext{
${ }^{40} \mathrm{O}$ entendimento que perfilhamos já foi caucionado pelo jurisprudência lusitana, que sufragou que "desde que o interesse do menor o reclame poderá este ser confiado aos cuidados de terceira pessoa, ainda que o menor possua algum dos progenitores em condições de lhe caber o exercício do poder paternal. 0 que importa é que se aconselhe a confiança do menor a pessoa diferente do progenitor." Ac. RLx de 20/10/2005 (Pereira Rodrigues), disponível em www.dgsi.pt.
} 


\section{REFERÊNCIAS}

AMORIM, Rui Jorge Guedes Faria. O Interesse do Menor: um Conceito Transversal à Jurisdição de Família e Crianças. Revista do CEJ. Lisboa. n.12 (2.sem.2009).

CUNHA, Paulo Ferreira da. Geografia Constitucional: Sistemas Juspolíticos e Globalização. Lisboa: Quid Juris, 2009.

DINIZ, João Seabra. Família Lugar dos Afetos. In: LEANDRO, Armando, LÚCIO, Álvaro Laborinho. Estudos em Homenagem a Rui Epifânio. Coimbra: Livraria Almedina, 2010.

LEAL, Ana Teresa. O Divórcio e as Responsabilidades Parentais. [Em Linha]. Lisboa: CEJ. [consult. 19 maio 2017]. Disponível em:

www.cej.mj.pt/cej/recursos/ebooks/familia/O_divorcio.pdf.

LÉVY, Pierre. Cibercultura. Trad. Carlos Irineu da Costa. $1^{\circ}$ Ed. São Paulo: Editora 34, 1999.

MALAMUTH, Neil/LINZ, Daniel/YAO, Mike. The Internet and Aggression: Motivation, Disinhibitory, and Opportunity Aspects. In: AMICHAI-HAMBURGER, Yair. The Social Net. Understanding Human Behavior in Cyberspace. Oxford: Oxford University Press, 2005.

MARTINS, Rosa. Responsabilidades Parentais no Século XXI: a Tensão entre o Direito de Participação da Criança e a Função Educativa dos Pais. Lex familiae. Revista Portuguesa de Direito da Familia. Coimbra. ISSN: 1645-9660. a.5, n.10 (2008), pp. 25-40.

MELO, Helena Gomes et. al. Poder Paternal e Responsabilidades Parentais. Lisboa, Quid Juris, 2009.

PINHEIRO, Jorge Duarte. O Direito da Família Contemporâneo. 3ª Ed. Lisboa, AAFDL, 2012.

RODRIGUES, Hugo Manuel Leite. Questões de Particular Importância no Exercício das Responsabilidades Parentais. Coimbra: Coimbra Editora, 2011.

ROUSSEAU, Jean-Jacques. Emílio. Trad. Pilar Delvaulx. Mem Martins: Publicações EuropaAmérica, 1990.

SIMÕES, Taborda, MARTINS, Rosa, FORMOSINHO, M. D. Regulação do Exercício do Poder Paternal: Aspectos Jurídicos e Avaliação Psicológica. In: FONSECA, António Castro et al - Psicologia forense. Coimbra. Livraria Almedina, 2006.

SOTTOMAYOR, Maria Clara. Regulação do Exercício das Responsabilidades Parentais em Caso de Divórcio. 5a Edição. Coimbra: Livraria Almedina, 2011.

SOTTOMAYOR, Maria Clara. Exercício conjunto das responsabilidades parentais: igualdade ou o retorno ao patriarcado. In: SOTTOMAYOR, Maria Clara e ALMEIDA, Maria Teresa. E foram felizes para sempre: uma análise crítica do novo regime jurídico do divórcio. Coimbra: Wolters Kluwer Portugal, 2010. 
SOTTOMAYOR, Maria Clara. Liberdade de Opção da Criança ou Poder do Progenitor?: Comentário ao Acórdão do Tribunal da Relação de Coimbra de 31 de Outubro de 2007. Lex Familiae. Revista Portuguesa de Direito da Família. Coimbra. a.5, n.9 (2008), pp. 56/57.

SOTTOMAYOR, Maria Clara. Qual é o Interesse da Criança? Identidade Biológica Versus Relação Afectiva. In: CORREIA, Paulo [et al.] Volume Comemorativo dos 10 Anos do Curso de PósGraduação “Proteção de Menores - Prof. Doutor F. M. Pereira Coelho. Coimbra: Faculdade de Direito da Universidade de Coimbra, Centro de Direito da Família, 2008

VILARDO, Maria Aglaé Tedesco e FERREIRA, Nuno. A Guarda Conjunta: Notas Comparativas sobre as Soluções Legais em Vigor na União Europeia e no Brasil. Lex Familiae: Revista Portuguesa de Direito da Família. 4, n.7 (2007), pp. 75-97.

WALL, Karin. Modos de Guarda das Crianças nas Famílias Portuguesas. [Em linha]. Lisboa: "Associação Portuguesa de Sociologia". [consult. 22 mar. 2018]. Disponível em: http://www.aps.pt/cms/docs_prv/docs/DPR462e00f42e652_1.PDF<.

MARTINS, Rosa. Responsabilidades Parentais no Século XXI: a Tensão entre o Direito de Participação da Criança e a Função Educativa dos Pais. Lex familiae. Revista Portuguesa de Direito da Familia. Coimbra. ISSN: 1645-9660. a.5, n.10 (2008), pp. 25-40.

Artigo convidado. Publicado em: 26.08.2019

\section{COMO FAZER REFERÊNCIA AO ARTIGO (ABNT):}

SILVA, Hugo Daniel da Cunha Lança. Colaboração privada na estruturação de obras públicas: a evolução dos regimes de empreitadas e a matriz de riscos. Revista Eletrônica do Curso de Direito da UFSM, Santa Maria, RS, v. 14, n. 2, e34907, maio./ago. 2019. ISSN 1981-3694. DOI: http://dx.doi.org/10.5902/1981369434907 . Disponível em: https://periodicos.ufsm.br/revistadireito/article/view/34907. Acesso em: dia mês. ano.

Direitos autorais 2019 Revista Eletrônica do Curso de Direito da UFSM

Editores responsáveis: Rafael Santos de Oliveira e Angela Araujo da Silveira Espindola

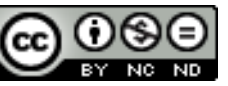

Esta obra está licenciada com uma Licença Creative Commons Atribuição-NãoComercial-SemDerivações 4.0 Internacional.

\section{SOBRE O AUTOR}

Hugo daniel da Cunha Lança Silva

Professor Adjunto no Instituto Politécnico de Beja, coordenador do curso de solicitadoria e coordenador do gabinete lusófono de direito do IPBeja. Doutor em Direito pela Universidade do Porto, desde 2015 e Investigador Doutorado Integrado no CEDIS Universidade Nova de Lisboa. 